\title{
Anthropogenic dissolved organic carbon and marine microbiomes
}

\author{
Maria Vila-Costa $\mathbb{1}^{1} \cdot$ Elena Cerro-Gálvez ${ }^{1} \cdot$ Alicia Martínez-Varela $^{1} \cdot$ Gemma Casas $^{1} \cdot$ Jordi Dachs $_{(\mathbb{D}}^{1}$
}

Received: 10 March 2020 / Revised: 12 June 2020 / Accepted: 30 June 2020 / Published online: 9 July 2020

(c) Springer Nature Limited 2020

\begin{abstract}
Thousands of synthetic chemicals and hydrocarbons are released to the marine environment composing the anthropogenic dissolved organic carbon (ADOC). Most ADOC is disproportionally hydrophobic, and consequently, its concentrations in the cell membranes are between a thousand and hundred million fold higher than those in the dissolved phase. Marine microorganisms respond to ADOC by multiple strategies ranging from ADOC degradation to detoxifying metabolisms. We argue that the increasing concentrations of ADOC in the oceans deriving from rivers, atmospheric deposition, and plastic leachates can have an effect on the health of the oceans and influence the major biogeochemical cycles, thus influencing the Earth system during the Anthropocene.
\end{abstract}

Human activity dramatically changes the chemosphere through contribution of synthetic compounds, as well as unnatural mobilization processes, such as industrial scale hydrocarbon extraction, combustion, and agriculture. Millions of man-made chemicals have been synthesized, of which 300,000 are currently under commerce [1]. Manmade chemicals include flame retardants, pesticides, herbicides, pharmaceuticals, musk fragrances, surfactants, sealants, plastics, plasticizers, and other plastic exudates, dioxins, food additives, antibiotics, among others. These synthetic chemicals, together with hydrocarbons associated with the extraction and use of fossil fuels, have been released to the environment during the Anthropocene following an exponential growth. As an example, it is estimated that the use of plastics during the past 15 years only, surpasses that used during the previous century [2]. On the other hand, current emissions of hydrocarbons coming from incomplete combustion of fossil fuels, such as those of polycyclic aromatic hydrocarbons, are significantly higher than in preindustrial ages. All together, these thousands of hydrocarbons and synthetic organic chemicals at trace

Supplementary information The online version of this article (https:// doi.org/10.1038/s41396-020-0712-5) contains supplementary material, which is available to authorized users.

Maria Vila-Costa

maria.vila@idaea.csic.es

1 Department of Environmental Chemistry, IDAEA-CSIC, Barcelona, Catalunya, Spain levels are continuously shaping the contemporaneous Earth chemosphere, including the marine environment. While coastal seawater is impacted by rivers and continental runoff leading to widespread occurrence of synthetic chemicals, such as plastic leachates, there is also a diffuse pollution to the global oceans by atmospheric deposition, which can account for large carbon fluxes (e.g., $400 \mathrm{TgC}$ year $^{-1}$ for aromatic hydrocarbons only, [3], Supplementary Fig. 1). Once in seawater, synthetic chemicals and hydrocarbons compose the anthropogenic dissolved organic carbon (ADOC).

The components of ADOC comprise relatively wellstudied chemicals, such as hydrocarbons, polychlorinated biphenyls, perfluoroalkyl substances, and organophosphate esters, among other chemicals and mixtures contributing to ADOC (Supplementary Table 1). Similar to the natural dissolved organic carbon (DOC), there are ADOC compounds of labile, semilabile, and refractory nature, the latter known as persistent organic pollutants. Turnover rates of ADOC components in marine systems can range from hours to centuries, but are poorly characterized for most chemicals. The known pool of ADOC is generally $<1 \mu \mathrm{M}$ [4], around two orders of magnitude lower than DOC concentrations, which generally ranges from 40 to $90 \mu \mathrm{MC}$ in open surface ocean. The reservoir of DOC in the oceans is of similar magnitude than atmospheric carbon dioxide $\left(\mathrm{CO}_{2} ; \approx 0.6 \times 10^{18} \mathrm{gC}\right.$; ref. [5]). Whereas marine microbial ecology and Earth system sciences generally consider only $\mathrm{CO}_{2}$ and biogenic DOC as important drivers of marine microbial communities, and their influence on climate and ecosystems, the specific 
characteristics and role of ADOC has largely been neglected.

Why shall we care about the effects of such diluted chemical compounds? Most ADOC is disproportionately hydrophobic, as measured by the octanol-water partition coefficients $\left(K_{\mathrm{OW}}\right)$, and this has biogeochemical implications. $K_{\mathrm{OW}}$ and bioaccumulation factors in planktonic organisms for ADOC compounds range from $10^{3}$ to $10^{8}$, which leads to ADOC concentrations in the (cell) membrane lipids to be between a thousand and hundred million fold compared to those in the dissolved phase (Supplementary Fig. 1). Comparatively, ADOC do not adhere to abiotic inorganic surfaces. Such large ADOC accumulation into cellular lipids do not apply for large pools of biogenic DOC, which is highly polar and thus soluble in seawater. ADOC will be preferentially accumulated in the cell membranes, thus ADOC is that fraction of DOC affecting the membrane fluidity and integrity, with potential for toxicological effects on microorganisms. These effects have been proven not only due to hydrocarbons, but also as the consequence of exposure to complex mixtures of ADOC components [4]. Hydrophobic ADOC is also especially susceptible for being sorbed to the surface of hydrophobic plastics, which can be leached back to seawater after plastic fragmentation, weathering, and transport in the marine environment.

Responses of marine microorganisms to ADOC compounds include a wide diverse battery of strategies from catabolic pathways to adaptive metabolisms that can be tracked using analytical, genomic, and molecular tools (Supplementary Fig. 1). Most of the microbial physiological responses to ADOC in the field have been studied in acute events, such as oil spills accidents or in coastal impacted sites, which represent a punctual large input of ADOC compounds to the marine environment. However, atmospheric deposition is a diffuse source of pollution to the open oceans driving the background low, but ubiquitous, concentrations of many ADOC components. Globally, atmospheric deposition inputs represent a greater contaminant mass than point sources. For instance, the yearly entrance of the aromatic fraction of ADOC to oceans by diffusive atmospheric deposition surpasses the amounts released by any marine accidental oil spill [3]. Plastic leachates have also been shown to be important in terms of carbon fluxes [6]. Microbial responses to background concentrations of ADOC compounds are just starting to be analyzed, and show how dynamic the ADOC pool is. There is an important biodegradation of $\mathrm{ADOC}$, including that derived from plastic leachates and atmospheric deposition in the surface ocean, promoting bacterial growth [6-8]. ADOC consumption can originate changes in communities' composition by promoting the growth of the opportunistic low-abundance microorganisms that are members of the rare biosphere [4]. Furthermore, consumption of many anthropogenic chemicals containing organic $\mathrm{P}, \mathrm{N}$, and $\mathrm{S}$ can alleviate nutrient limitation, and thus perturbing essential nutrient biogeochemistry [9, 10]. Other studies show negative effects on photosynthesis and toxic effects on specific heterotrophic bacteria groups [4, 11, 12]. Many of these effects are related to the strong accumulation of hydrophobic ADOC in the cell membranes.

The growth of some taxa on ADOC, and the decrease of other taxa due to toxicity, induce changes in the functionality and structure of the bacterial communities, which can be translated to changes in the ecosystem services. Consequently, the ADOC perturbation of the marine microbiome is coupled to the carbon and nutrient biogeochemical cycles $[6,8]$. This influence, together with ADOC effects on primary production $[11,12]$, points to an ADOC perturbation of the ocean metabolism (Supplementary Fig. 1). These results suggest that microbial responses to ADOC can be taken as a proxy of ocean health. The dispersed nature of the pollution restricts direct pollutant monitoring, and developing microbial and genomic indicators of such chronic pollution, and their effects will be a useful tool. Nevertheless, the effects of ADOC on ocean health are barely known and have received less attention that those of other environmental stressors due to the complexity of ADOC and the elusive appropriate approaches to comprehensively asses ADOC perturbations [13].

Even though the emissions of individual components of ADOC may increase or decrease over time due to changes in products in commerce or international legislation, the total emissions of synthetic chemicals and concentrations of ADOC will continue to increase exponentially, in pace with economic development, during the coming decades. Under this scenario, the influence of ADOC on microbial communities and biogeochemical cycles will become more important. We claim that a comprehensive study comprising the characterization of ADOC sources, biogeochemistry, effects, and feedbacks with key biogeochemical cycles is urgent in order to understand and quantify this vector of environmental global change, with increasing relevance in the Earth system.

\section{Compliance with ethical standards}

Conflict of interest The authors declare that they have no conflict of interest.

Publisher's note Springer Nature remains neutral with regard to jurisdictional claims in published maps and institutional affiliations.

\section{References}

1. Wang Z, Walker GW, Muir DCG, Nagatani-Yoshida K. Toward a global understanding of chemical pollution: a first comprehensive 
analysis of national and regional chemical inventorie. Environ Sci Technol. 2020;54:2575-84.

2. Geyer R, Jambeck JR, Law KL. Production, use, and fate of all plastics ever made. Sci Adv. 2017;3:e1700782.

3. González-Gaya B, Fernández-Pinos MC, Morales L, Méjanelle L, Abad E, Piña B, et al. High atmosphere-ocean exchange of semivolatile aromatic hydrocarbons. Nat Geosci. 2016;9:438-42.

4. Cerro-Gálvez E, Casal P, Lundin D, Piña B, Pinhassi J, Dachs J, et al. Microbial responses to anthropogenic dissolved organic carbon in the Arctic and Antarctic coastal seawaters. Environ Microbiol. 2019;21:1466-81.

5. Carlson CA, Hansell DA. DOM sources, sinks, reactivity, and budgets. In: Carlson CA, Hansell DA. editors. Biogeochemistry of marine dissolved organic matter. San Diego (USA): Academic press; 2015. p. 65-126

6. Romera-Castillo C, Pinto M, Langer TM, Álvarez-Salgado XA, Herndl GJ. Dissolved organic carbon leaching from plastics stimulates microbial activity in the ocean. Nat Commun. 2018;9:1430.

7. Cerro-Gálvez E, Sala MM, Marrasé C, Gasol JM, Dachs J, VilaCosta M. Modulation of microbial growth and enzymatic activities in the marine environment due to exposure to organic contaminants of emerging concern and hydrocarbons. Sci Total Environ. 2019;678:486-98.
8. González-Gaya B, Martínez-Varela A, Vila-Costa M, Casal P, Cerro-Gálvez E, Berrojalbiz N, et al. Biodegradation as an important sink of aromatic hydrocarbons in the oceans. Nat Geosci. 2019;12:119-25.

9. Vila-Costa M, Sebastián M, Pizarro M, Cerro-Gálvez E, Lundin D, Gasol JM, et al. Microbial consumption of organophosphate esters in seawater under phosphorus limited conditions. Sci Rep. 2019;9:1-11.

10. Cerro-Galvez E, Roscales JL, Jiménez B, Sala MM, Dachs J, VilaCosta M. Microbial responses to perfluoroalkyl substances and perfluorooctanesulfonate (PFOS) desulfurization in the Antarctic marine environment. Water Res. 2020;171:115434.

11. Fernández-Pinos MC, Vila-Costa M, Arrieta JM, Morales L, González-Gaya B, Piña B, et al. Dysregulation of photosynthetic genes in oceanic Prochlorococcus populations exposed to organic pollutants. Sci Rep. 2017;7:8029.

12. Tetu SG, Sarker I, Schrameyer V, Pickford R, Elbourne LD, Moore LR, et al. Plastic leachates impair growth and oxygen production in Prochlorococcus, the ocean's most abundant photosynthetic bacteria. Commun Biol. 2019;2:1-9.

13. Buttigieg PL, Fadeev E, Bienhold C, Hehemann L, Offre P, Boetius A. Marine microbes in $4 \mathrm{D}$ - using time series observation to assess the dynamics of the ocean microbiome and its links to ocean health. Curr Opin Microbiol. 2018;43:169-85. 